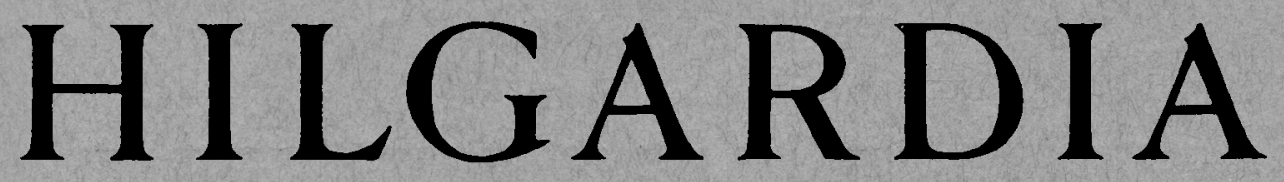

A Journal of Agricultural Science Published by the California Agricultural Experiment Station

\title{
CASCA CHINENSIS, AN INTERNAL PARASITE OF CALIFORNIA RED SCALE
}

S. E. FLANDERS, J. L. GRESSITT, and T. W. FISHER 
Casca chinensis, a parasite of red scale on citrus in south China, has been regarded as a potential control of red scale in California since its discovery in 1906. This review of the attempts that have been made to import and propagate $C$. chinensis presents what has been learned to date about this endoparasite. Outdoor propagation in south China has been successful; however, reproduction in the laboratory and importation and colonization of the species in California have so far failed because the particular condition or conditions necessary for reproduction of the male remain unknown. This failure was occasioned by an unusually cryptic aspect of the sex differentiation in host-parasite relations characteristic of certain Hymenoptera. Propagation experiments are described, and new avenues of investigation are suggested. 


\title{
H I L G A R D I A \\ A Journal of Agricultural Science Published by \\ the California Agricultural Experiment Station

\begin{tabular}{lll}
\hline VoL. 28 & NOVEMBER, 1958 & No. 3 \\
\hline
\end{tabular}

\section{CASCA CHINENSIS, AN INTERNAL PARASITE OF CALIFORNIA RED SCALE ${ }^{1,3}$}

\author{
S. E. FLANDERS, J. L. GRESSITT, and T. W. FISHER ${ }^{3}$
}

\section{INTRODUCTION}

'THE DISCOVERY in 1906 of a microscopic wasp, Casca chinensis Howard, parasitic within the body of the California red scale, Aonidiella aurantii (Mask.), on citrus in south China, initiated a series of attempts extending over the following fifty years to introduce and establish the parasite in California citrus orchards.

This interest in Casca chinensis is sustained by three possibilities: its development is apparently limited to California red scale; it seems able to survive on very low densities of this scale; and it should prove adaptable to the environment of the California citrus orchard. Three species of parasites associated with it in south China are now established on red scale in the citrus orchards of California.

The purposes of this presentation are (1) to evaluate the role of Casca chinensis in China as a control of California red scale, (2) to review the various attempts to introduce the parasite into California and the biological tests involved, and (3) to suggest further lines of investigation.

\section{THE PARASITE COMPLEX ON RED SCALE IN CHINA}

All information concerning the parasite complex of red scale has accrued since the introduction into California of the first parasite species in 1900 . In that year George Compere, foreign explorer for the California State Board of Horticulture, sent to California from Hong Kong a small orange tree infested with parasitized red scale (Flanders, 1949). ${ }^{4}$ This scale yielded 647 microscopic wasps, presumably Aspidiotiphagus citrinus (Craw), which were released in the citrus orchards of Los Angeles and Orange counties.

${ }^{1}$ Submitted for publication July $26,1956$.

${ }^{2}$ Paper No. 976, University of California Citrus Experiment Station, Riverside.

${ }^{3} \mathrm{Mr}$. Flanders is Professor of Biological Control and Entomologist in the Citrus Experiment Station, Riverside; Mr. Gressitt, formerly Assistant Entomologist in the Gitrus Experiment Station, Riverside, is Entomologist, Bishop Museum, Honolulu; and Mr. Fisher is Assistant Entomologist in Biological Control in the Citrus Experiment Station, Riverside.

"See "Literature Cited" for citations, referred to in the text by author and date. 
In 1905 Compere collected Comperiella bifasciata How. and an Aphytis (presumably $A$. lingnanensis Comp.) in the vicinity of Hong Kong and sent them to California for propagation and release.

Unfortunately, none of these natural enemies of California red scale became established in California as a result of Compere's shipments. Comperiella bifasciata was first established in 1942 as a result of collections

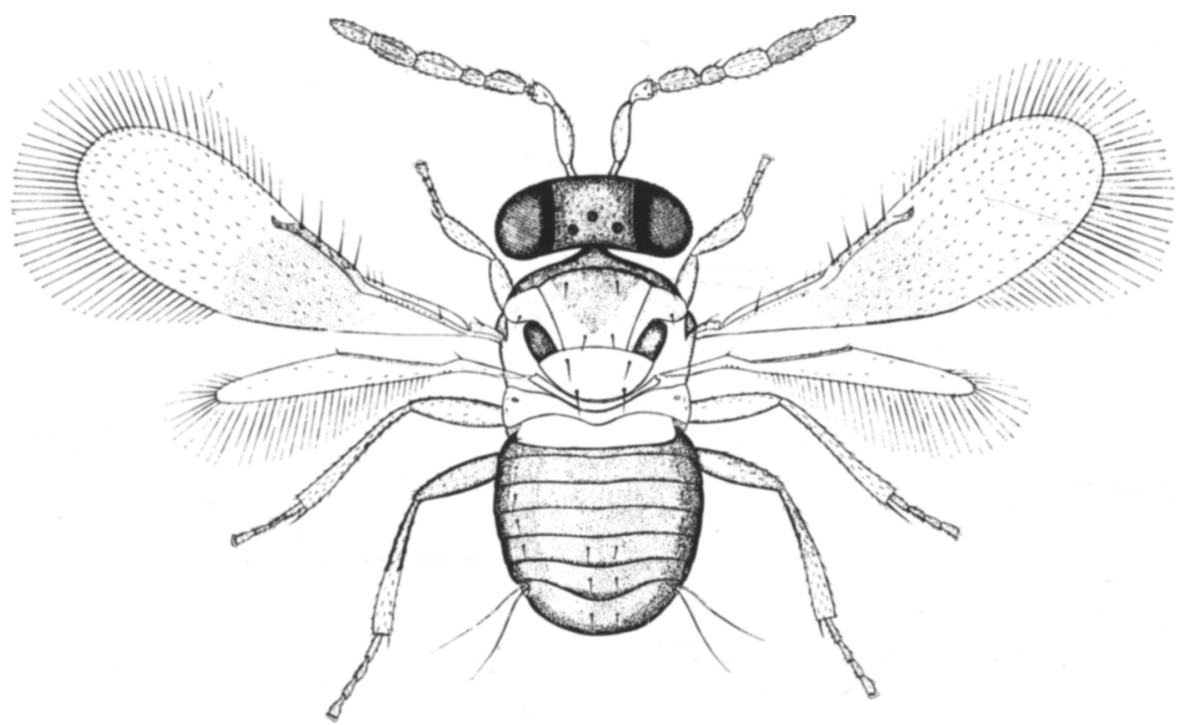

Fig. 1. Casca sp. drawn by H. Compere. In the female of $C$. chinensis How., unlike the species illustrated, all legs are pallid, and the scutellum, metanotum, and propodeum are glistening white.

made by J. L. Gressitt near Canton in 1941. Aphytis lingnanensis was established in 1948 as a result of Gressitt's collections near Canton in 1947.

Casca chinensis was discovered on coccid-infested plants collected by Compere in Kwangtung Province and sent to California in 1906. In an accompanying letter he called attention to evidence of the presence of a new parasite in the red scale on a cycad. This led to the identification and description of $C$. chinensis by L. O. Howard in 1907 and heightened the interest in the search for parasites of red scale in south China.

From 1947 through 1951, Gressitt and his assistants, working under the direction of S. E. Flanders, searched for citrus-infesting red scale in the Chinese provinces of Fukien, Hunan, Hupeh, Kiangsi, Kwangsi, Kwangtung, and Szechuan, and in Formosa and Japan as well. Parasitized red scale collected from citrus in China yielded the following species: Anabrolepis sp., Adelencyrtus sp., Aphytis lingnanensis Comp., A. hispanicus (Mercet), Aspidiotiphagus citrinus (Craw), Casca chinensis How., C. wanhsiensis Comp., Comperiella bifasciata How., and Prospaltella perniciosi Tower. In 1949 P. perniciosi became the third parasite established in California (Flanders, $1953 b)$. 
Red scale in the highly productive citrus areas of Szechuan, around latitude $31^{\circ} \mathrm{N}$, was extremely difficult to find. The few infestations that were found yielded 284 Casca wanhsiensis and 52 Comperiella bifasciata. These two species were the only primary parasites of red scale obtained from this region. Several of the scales, however, had apparently been parasitized by Prospaltella sp. During the last half of April, 1949, an intensive examina-

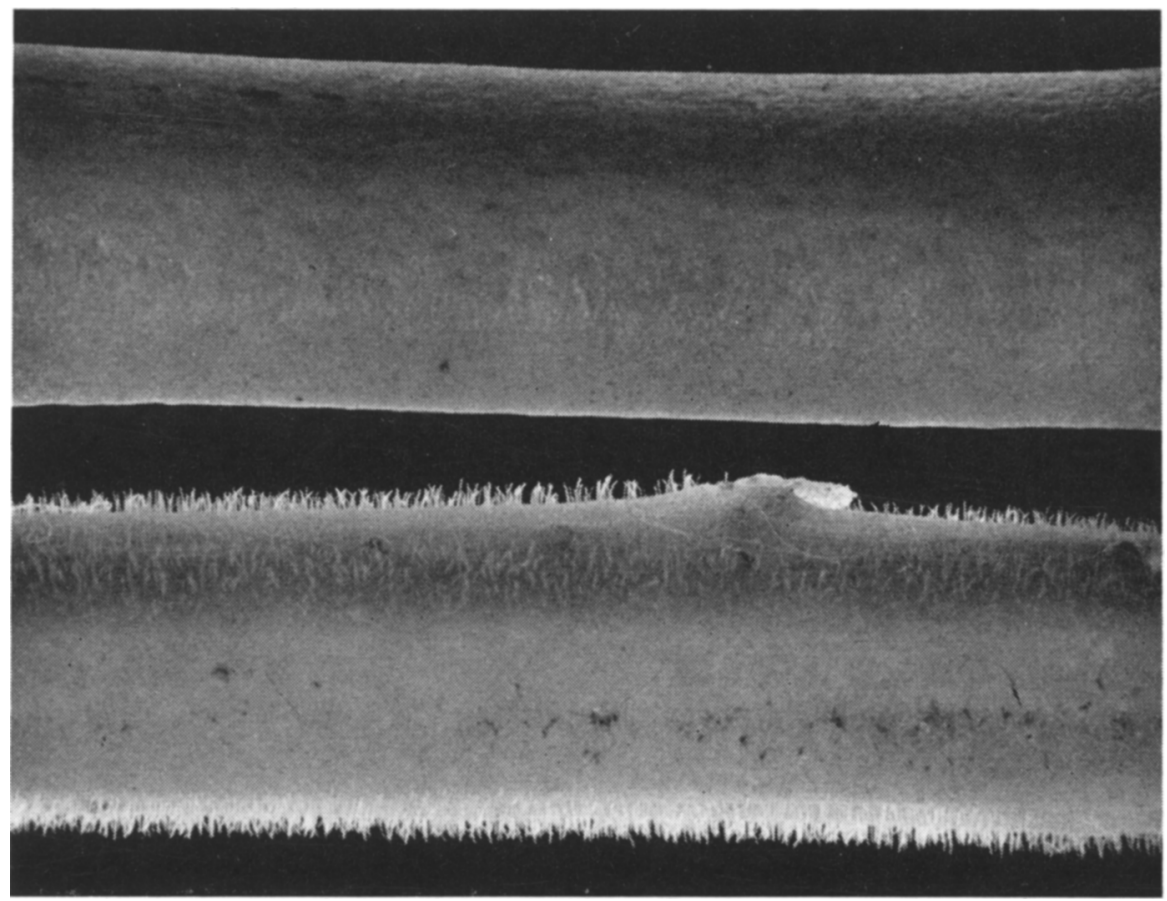

Fig. 2. Sections of green pummelo twigs representing two varieties, glabrous and pubescent. California red scale develops readily on both varieties. The pubescent section was removed from a plant of the Gong variety of pummelo, which was very heavily infested with red scale. The individual plant hairs vary from $1 / 4$ to $1 / 3 \mathrm{~mm}$ in length, approximately the thickness (height) of the body of the Casca female. As it is formed, the red scale cover is extended under the pubescence, lifting it slightly. When fully extended, the scale cover bears about 40 of the plant hairs.

tion of citrus in the vicinity of Chengtu yielded 13 red scales, 9 of which appeared to have been parasitized by $C$. wanhsiensis. All of these scales were located between two citrus leaves.

In Kwangtung Province, around latitude $23^{\circ} \mathrm{N}$, the red scale was found more readily. This more frequent appearance of red scale on citrus appears correlated with the presence of artificially established nests of the red citrus ant, Oecophylla smaragdina, and possibly the more frequent occurrence of grime on the twigs and foliage of pummelo (Citrus grandis). The heaviest red scale infestations noted, however, occurred on three plants of the "Gong" variety of pummelo, which were free of dust and grime; this variety is characterized by extremely pubescent twigs (fig. 2 ). 
Casca wanhsiensis as a parasite of red scale is replaced in Kwangtung Province by $C$. chinensis. C. wanhsiensis occurs here on citrus in association with $C$. chinensis but not as a parasite of red scale. These two species of Casca are of particular interest because (1) they are morphologically identical except in color; (2) unlike the other endoparasites of red scale they are not solitary in development but are capable of developing gregariously ; (3) they differ from each other in their distribution and ecological habits; and (4) at least one of these two species consists of host-determined races.

The marked difference in distribution of the two red scale-feeding forms of Casca may be correlated with differences in the developmental habits of the male. Under laboratory conditions, the male of $C$. wanhsiensis was readily propagated, the adult emerging from the red scale coincidently with the emergence of the female, the sex ratio being predominantly male. The original stocks from China consisted of field-collected material which yielded enough of both sexes to start a culture under mass production conditions. This was never the case with $C$. chinensis. Males of $C$. chinensis have yet to be reared from red scale.

It is significant that with a species of Casca parasitic on the yellow scale, Aonidiella citrina (Coq.), the male, as in C. wanhsiensis, emerges coincidently with the female. The yellow seale Casca, which is also associated with C. chinensis on citrus in Kwangtung Province, is structurally identical with C. wanhsiensis and C. chinensis (of which it may be a host-determined race) but is characterized by white axillae in the female (see footnote 6 , page 70 ).

Laboratory tests with these three species show, however, that the production of males by unmated females in the absence of mated females is impossible. The mass culture of the yellow scale Casca and C. chinensis might have been initiated if the number of imported scales yielding both sexes had approximated the number of red seales yielding C. wanhsiensis and had been handled in like manner. Unfortunately, no thorough tests were made on the production of males by the unmated female of $C$. wanhsiensis.

The evolutionary divergence in habit of these structurally indistinguishable species may be correlated with their dispersion from a common original habitat. This habitat is presumably located on the plateau of Yünnan (fig. 3) at the eastern end of the Himalayas, a region considered to lie within the original habitat of citrus (Tanaka, 1954) and of citrus-infesting red scale. ${ }^{5}$

It is noteworthy that Filippo Silvestri during his employment by the University of California as parasite collector spent the last week of February, 1925, in the vicinity of Yünnanfu (Kumming) examining lemon and orange trees for red scale. Although he found none, he recommended a thorough search of the Yünnan Plateau for the red seale and its parasites.

Casca chinensis probably originated on citrus-infesting red scale in the drainage system of the Si Kiang (Yung Hsi) (fig. 3). C. wanhsiensis as a parasite of citrus-infesting red scale is probably indigenous to the drainage system of the upper Yangtze Kiang. It is significant that the headwaters of the Si Kiang and the Yangtze Kiang almost join each other at the city of Chengkiang southeast of Yünnanfu. The isolating dispersion of Casca popu-

\footnotetext{
${ }^{5}$ G. F. Ferris, personal communication.
} 
lations northward down the Yangtze system and eastward down the Si system would tend to promote the development of distinctive differences in color and in habit. It is curious that on eitrus in the lower reaches of the Si Kiang the non-red-scale-feeding form of $C$. wanhsiensis exists in association with $C$. chinensis and the structurally indistinguishable yellow seale Casca.

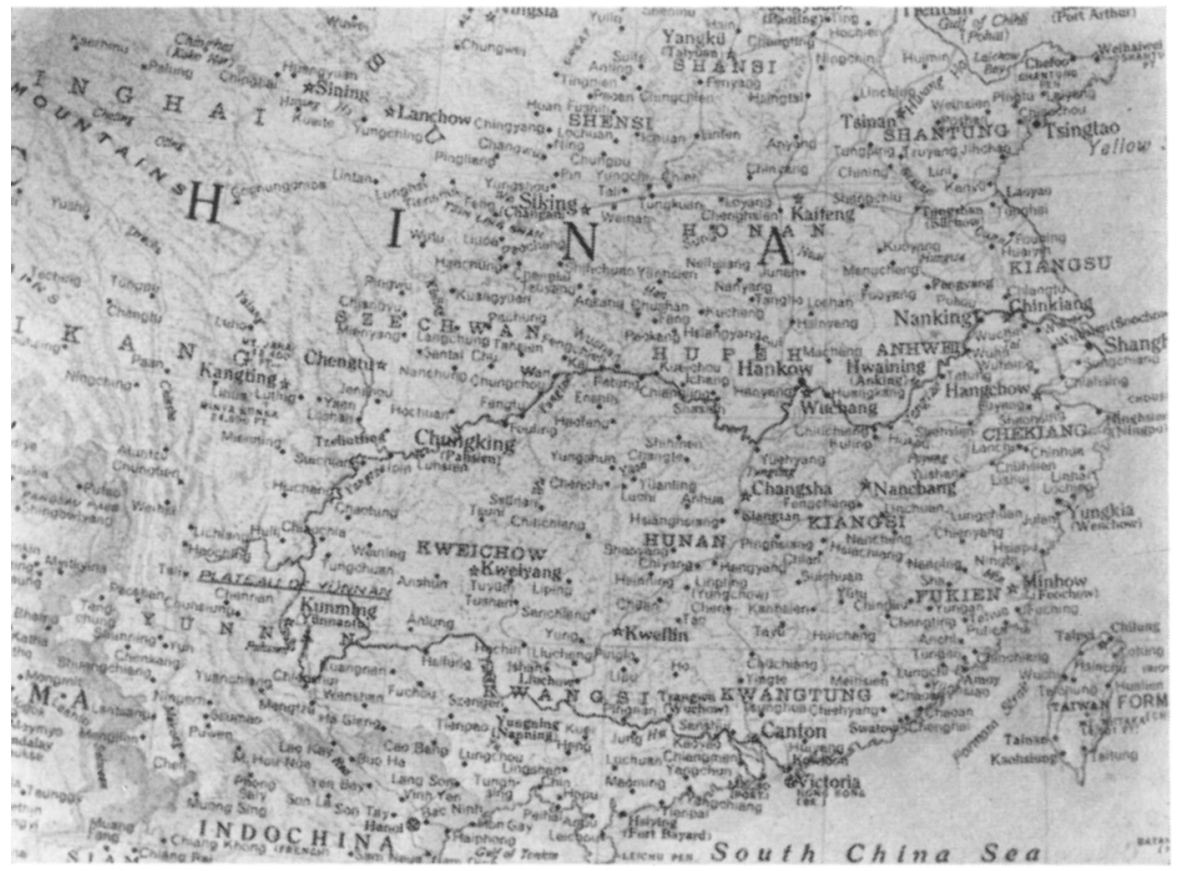

Fig. 3. Map of China, showing the drainage basins of the Yangtze and Yung Hsi (Si Kiang) rivers. The red scale-feeding Casca wanhsiensis inhabits the great citrus-growing area in the triangle formed by the cities of Chunking, Chengtu, and Wan. It is apparently the dominant parasite of red scale in that area-the red scale being very scarce. The red scale-feeding $C$. chinensis inhabits the citrus-growing area south and east of Canton. $C$. chinensis is the dominant parasite only under exceptional conditions.

The noneconomic status of red seale on citrus in Kwangtung Province was noted by George Compere in 1906, F. Silvestri in 1925, Gressitt in 1941, 1948, 1949, and 1950, and Flanders in 1953-54. Each of these workers concluded that the natural enemies of the red scale were responsible for its generally very low density. Flanders' studies during the 9-month period ending July 1, 1954, showed, however, that the generally effective natural enemies, if any, were not parasitic but presumably predatory. Two exceptions were observed. One was a relatively heavy infestation of red scale on an isolated pummelo tree in a Chinese village, which appeared to be almost completely parasitized by Aspidiotiphagus citrinus. Again, in a small pummelo orchard of about 20 trees near Man Hang Village, Tai Po, the red scale on several heavily infested branches was observed to be highly para- 
sitized by Casca chinensis and Prospaltella perniciosi, species which subsequently destroyed the infestation.

\section{GENERAL CHARACTERISTICS OF CASCA CHINENSIS}

The capacity of Casca chinensis to control red scale out of doors was demonstrated by Gressitt in 1950 in the insectary garden of Lingnan University in Canton. This control occurred in an outdoor culture of $C$. chinensis, which was initiated in the spring of 1948 and ended December, 1950. Political conditions put an end to production.

The fact that a specific parasite, such as Casca chinensis appears to be, can maintain itself on a host population which is kept at a low density by other agencies indicates a high searching capacity. We can assume therefore that $C$. chinensis alone is able to hold the host population at an equally low density, its action as a controlling factor also being governed by the density of the population controlled (Nicholson, 1933).

Some of the characteristics of Casca chinensis that favor such control are as follows:

1. The searching, reproductive life of the female is relatively long (one to two months). (It is found on citrus in the apparent absence of red scale.)

2. It is active at temperatures ranging from $50^{\circ}$ to $90^{\circ} \mathrm{F}$.

3 . At very low host densities the proportion of females is high.

4. As many as eight females may complete their development and emerge from a single mature scale.

5. It is multivoltine in relation to its host, having up to three generations to one of its host.

6. It develops in all larval stages of the scale and in the mature female. At $80^{\circ} \mathrm{F}$, when its eggs are deposited in the first-instar host the life cycle is 27 days; when its eggs are deposited in mature hosts the life cycle is 21 days.

Thus, in south China Casca chinensis is part of a complex of natural enemies that operates to keep red scale populations on susceptible citrus at very low densities (Flanders, 1954). This situation is to be expected in the native habitat of a scale insect. That south China is the natural habitat of red scale, as supposed by Quayle (1911), is definitely indicated if the distribution of its supposedly specific parasite, $C$. chinensis, ${ }^{6}$ is limited to that area, as is apparently the case.

Casca chinensis is the only intensively studied parasite of red scale whose life history presents a problem so puzzling as to defy solution. The species

\footnotetext{
${ }^{6}$ Compere (1953) lists nine species of Casca. Under field conditions, the various known species of Casca appear reproductively host-specific. Occasional parasitism of one species of scale by the habitual parasite of another species occurs commonly with diaspine scale insects. Varying degrees of occasional parasitization occur under laboratory conditions. C. smithi Comp., a habitual parasite of Chrysomphalus aonidum (Silvestri, 1928), is very rarely successfully parasitic on California red scale but will reproduce for a generation or two on Chrysomphalus bifasciculatus. Silvestri (1928) in a discussion of the natural enemies of citrus scale insects in China reported $C$. chinensis as a parasite of Aonidiella aurantii under the name Casca n. sp. His thought that $C$. chinensis was parasitic on Lepidosaphes beckii Newm. is now known to be erroneous (Compere, 1953).

In the fall of 1953, a Casca, which in 1951 had been imported from Formosa as a parasite of the yellow scale on Gardenia and of Aonidiella messengeri McK. on Bladhia, was
} 
is biparental and, as in certain other aphelinids, the mated female produces only females, the male being produced by the unmated female. When a fertilized $C$. chinensis egg is deposited free in the body fluids of red scale, embryonic development takes place; when an unfertilized egg is thus deposited, however, embryonic development is immediately inhibited, further development being dependent on circumstances (at present unknown) which counteract that inhibition. A similar situation supposedly exists with the species of Casca parasitie in the yellow scale and with $C$. wanhsiensis.

\section{ATTEMPTS TO INTRODUCE CASCA CHINENSIS INTO CALIFORNIA}

Beginning in 1906 with the discovery by George Compere of Casca chinensis as a parasite of red scale in south China, six abortive attempts have been made to introduce it into California. In addition to the difficulties involved in finding suitably infested and parasitized plant material for shipment and in propagating the imported parasites, two conditions prevailed before 1941, which hampered the efforts of workers in this field: one was the prohibition on the shipment of citrus plants or any portion thereof to California; the other, the universal lack of knowledge concerning certain physiological and ecological phenomena involved in the parasitization of coccids.

Early Attempts. Of the four attempts made before 1941, only the first was fruitful in that it resulted in the description by Howard (1907) of a new genus and new species, which he designated Casa chinensis.

The phenomena that proved to be critical factors in the early failures to introduce from China one or more of the parasites of California red scale are:

1. The lack of accurate identification of species.

2 . The existence within a parasitic species of host-determined races, as with Aspidiotiphagus citrinus, Prospaltella perniciosi, and Comperiella bifasciata.

3 . The existence of geographical races differing in the level of host density they maintain, as with Aphytis maculicornis (Masi) and A. mytilaspidis (LeBaron) (Flanders, 1957).

4. The plant-induced immunization of a host to the development of endoparasites such as Habrolepis rouxi Comp. and Comperiella bifasciata (the degree of immunization in red scale on cycad varying from 50 per cent with C. bifasciata to more than 90 per cent with $H$. rouxi).

5 . The inability of the mated female parasite to produce male progeny, the male not being able to develop under conditions suitable for the development of the female, so that the production of males is limited to the unmated female, as in Coccophagus scutellaris (Dal.) and Physcus testaceous Masi (Flanders, 1937, 1957).

found in south China parasitizing yellow scale on pummelo and wampei (Clausena lansium). The male differs from that of $C$. chinensis in that the color pattern is like that of C. smithi with a blackish "neckerchief" mark on the thorax extending to a point midway between the blackish axillae. $C$. smithi, however, is distinctive in that the width of the fuscous-free area between the "neckerchief" and the axillae is less than the width of the axillae. The $C$. chinensis male resembles the male of $C$. wanhsiensis, both being characterized in life by the gold color of the scutellum. 
The discovery of Casa chinensis and the first attempt to introduce it into California were made in $1906^{7}$ by George Compere who was employed jointly by the governments of Western Australia and California to obtain natural enemies of California red scale and other pests of agriculture. In a letter

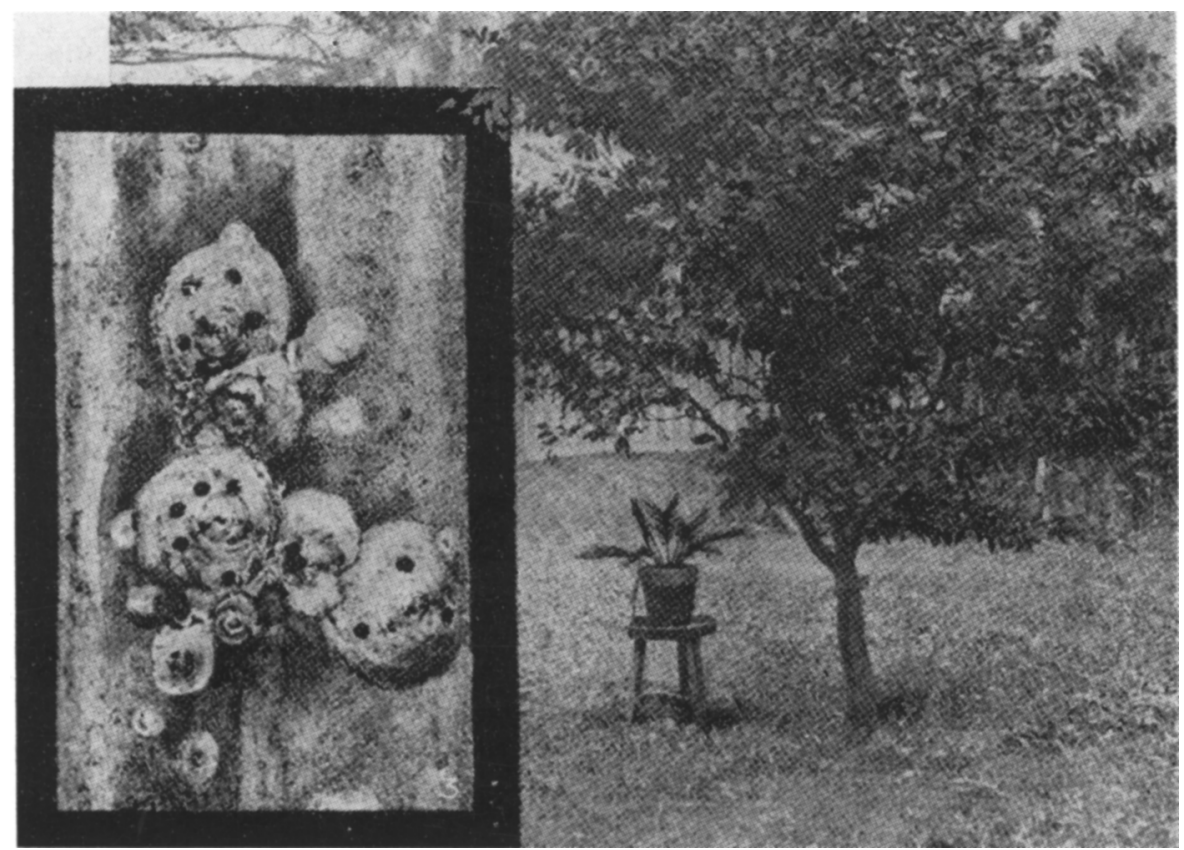

Fig. 4. On the stool is a "sago palm," Cycas revoluta, infested with Florida red scale, Chrysomphalus aonidum, parasitized by Casca smithi. This was sent to Hawaii in 1906 by George Compere on the same boat that carried to California a "sago palm" bearing California red scale parasitized by $C$. chinensis. The infested plant under the citrus tree illustrates the method of parasite colonization then used (Craw, 1907). Inset shows multiple emergence holes characterizing diaspine scales parasitized by the species of Casca.

concerning a shipment of coccid-infested plants to Elwood Cooper, the California State Horticultural Commissioner, he wrote:

There is also sent... in cool chamber, one small palm tree [undoubtedly the "sago palm," or cycad, Cycas revoluta (fig. 4)] which contains a few red scale...there is at work one of the most remarkable parasites I have yet found upon this scale; have counted as many as five exit holes in a single scale. The parasite itself $I$ have not yet seen, there being so few scales on the plant that I do not want to waste a single specimen. This tree I secured at a nursery and it is a good illustration of how much red scale there is in this country, it being all that $I$ was able to find during 8 days of searching; not another specimen was noticed... [the parasites] must be very small in order for five of them to make a living under one red scale, the most of the scales showing three holes.

After the cycad reached the State Insectary at Sacramento, two female parasites, probably reared from one of the red scales, were sent for identification to L. O. Howard, who published his description in 1907.

' Harold Compere, unpublished data. 
Later efforts, made in 1924,1932 , and 1940, served only to point up the difficulties involved in introducing the parasite. Although Filippo Silvestri explored south China for nine months in 1924-25 and made a particular effort to secure specimens of Casca chinensis, he was able to send to California only one shipment, a potted cycad bearing a few parasitized California red scale on which he had observed three females of this species of Casca.

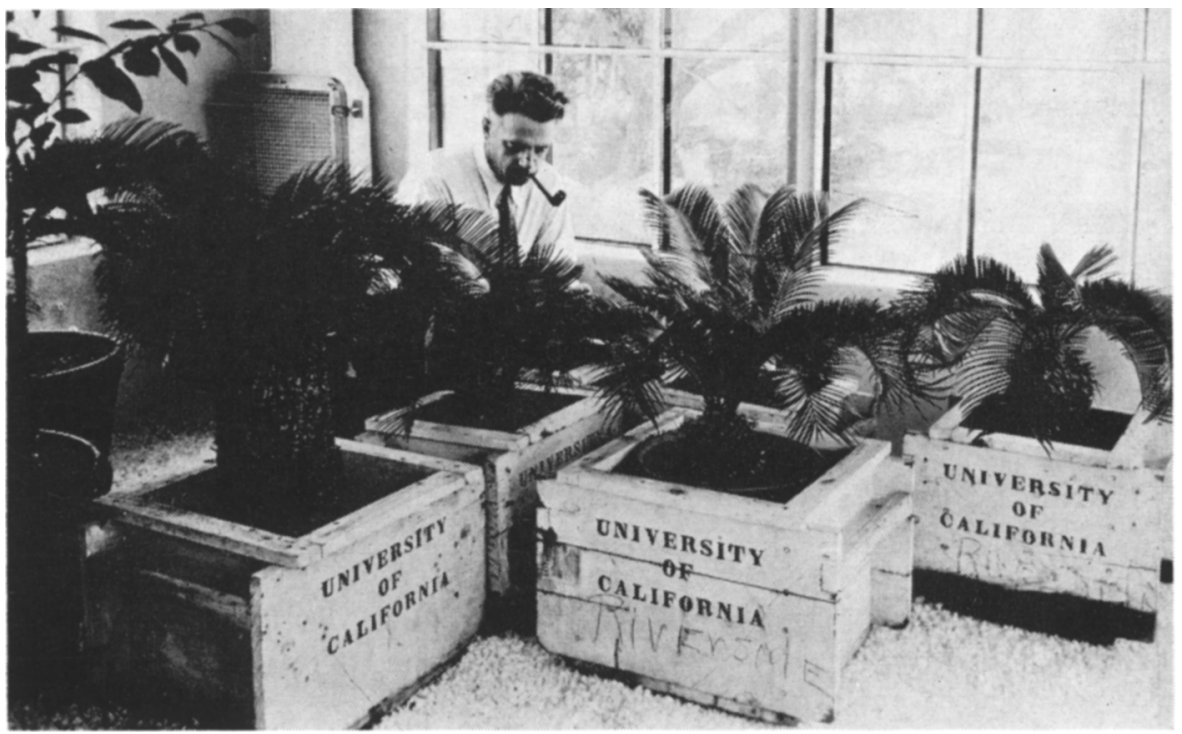

Fig. 5. Six cycads in the Quarantine Insectary at Riverside. These plants, after being infested with red seale, were taken to China by $\mathrm{H}$. Compere and inoculated with Casca chinensis and Comperiella bifasciata. Since these parasites did not develop, the California red scale was thought to be different from the red scale in China.

Because of this observation, he informed H. S. Smith that it was a shipment of great importance. The infestations on the cycad, however, consisted largely of Florida red scale parasitized by $C$. smithi, and, as is now known, it is extremely unlikely that any $C$. chinensis that may have emerged would have reproduced.

Like earlier investigators, Silvestri found infestations of red scale on Citrus to be scarce, although he reported finding two heavily infested pummelo trees in Foochow. These, he wrote later, seemed to have been reduced by predators, although Aphytis and Comperiella were present.

In 1932 Harold Compere made another attempt, using a new approach to the problem. His main objective was to determine definitely whether Casca really attacked the California red scale and to bring the parasite home if he could. He took with him from California six caged cycads (fig. 5) infested with pure cultures of California red scale. Finding what he called the "headquarters of Casca" on Flower (Fati) Island near Canton, he collected red scale on $C y c a s$ revoluta, which yielded $C$. chinensis. He released on the infested cycads brought from California the females of $C$. chinensis 
and Comperiella bifasciata the only parasites of California red scale that he found which were known "taxonomically" not to occur in California. It is noteworthy that the owner of a plant nursery on Fati Island gave Compere an account of Silvestri's visit and his purchase of a red scaleinfested cycad, an infestation parasitized by C. chinensis (Silvestri, 1928).

In 1940 arrangements to import parasitized red scale on citrus leaves and twigs, made in coöperation with the U. S. Bureau of Entomology and Plant Quarantine and Lingnan University in Canton, resulted in the introduction into California of Comperiella bifasciata. At this time a fourth attempt was made to secure Casca chinensis, but the emphasis was on the importation of Comperiella bifasciata because of the success of the Japanese race of this species in controlling yellow scale (Aonidiella citrina Coq.) in California citrus orchards (Flanders, 1948).

Since the arrangements called for the importation of red scale on citrus leaves and twigs, and since these parts of the citrus plant were likely to be infested with citrus canker, one generation of the parasites was propagated in the U. S. Department of Agriculture quarantine laboratory in Hoboken, N.J., on red scale-infested lemons sent from California; the adults of this generation were sent to California for further propagation. By this arrangement, Comperiella bifasciata was successfully introduced into California. All efforts to propagate Casca chinensis, however, were unsuccessful. No members of this species were sent alive to California.

Although the red scale-feeding form of Comperiella bifasciata was released in California citrus orchards by the hundreds of thousands and the species became well established in the inland citrus areas, it only occasionally destroyed large numbers of California red scale (Flanders, 1944). However, since $C$. bifasciata had become established in the arid parts of California, it seemed probable that the only known parasite of red scale remaining in south China but not occurring in California might also prove adaptable to California conditions if released in large numbers. The introduction of Casca chinensis was therefore again attempted.

The Biological Problem. The fifth and sixth attempts to obtain Casca chinensis are discussed in considerable detail because of the problems involved. During the fifth attempt, the collection of red scale in south China was handled by J. L. Gressitt, working under the direction of S. E. Flanders, who handled the material as Gressitt sent it to California.

It was during the fifth attempt that it became apparent that before Casca chinensis could be introduced and established in California it would first be necessary to determine the parasite's method of producing males. This basic biological problem proved to be extremely baffling. Until then the few facts known about $C$. chinensis were simply that it occurred in south China, that it was relatively rare, and that the female developed gregariously as an endoparasite in low densities of California red scale on eitrus and Cycas revoluta.

During the fifth attempt, which extended over the years 1948-49 and 1950, the following observations were made: 
1. Females that emerged under laboratory conditions from field-collected red scale would not reproduce under any known circumstances.

2. Females that had emerged under field conditions would reproduce in red scale under laboratory conditions for one generation, which was entirely female.

3. Under certain outdoor circumstances, continuous reproduction at a high percentage of parasitization was obtainable by proper manipulation of red scale populations on citrus, cycads, and potato tubers. Under such circumstances, a few Casca males, presumably $C$. chinensis, were present.

4. The production of males was not obtainable indoors.

5. The developing Casca female serves as a host for Marietta sp. and for the males of Prospaltella spp.

Additional findings, made during the sixth attempt, which extended over the years 1954-1955 and the first three months of 1957, were as follows:

1. Adult males and females of Casca chinensis occurred together on the same citrus tree in a ratio of 10 females to 1 male.

2. Laboratory-emerged females when mated with field-collected males produced an entirely female generation.

3. Unmated females oviposited more or less readily in red scale, but such eggs showed no embryonic development, although they apparently remained viable for an indefinite period.

4. Male development did not appear to be correlated with the presence in the red scale of other species of parasites.

5 . No other insects observed in association with red scale showed any evidence of having served as a host of the male (in one instance an unmated Casca female oviposited in the egg of the coniopterygid Spiloconis picticornis, but no development occurred).

In both the fifth and sixth attempts, the highest natural abundance of Casca chinensis noted occurred on citrus where the red scale population had been inereased through association with the red citrus ant, Oecophylla smaragdina. The first instance of the association was observed at Lo-kongtung, near Canton, where a relatively heavy infestation of red scale occurred on orange trees rather than on pummelo, as is usually the case. At Lo-kongtung the red citrus ant has for hundreds of years been used on oranges to control beetles, caterpillars, and plant bugs. The practice each spring of transferring the complete nest of the ant from wild host plants to the orange tends to maintain red scale infestations that are much cleaner and healthier than those on ant-free trees. The ant colonies on citrus are short-lived, presumably because the coccids producing the honeydew essential for their continued existence are absent.

It is significant that the only citrus plantings in which more than a dozen or so red scales yielding Casca chinensis were found in months of searching were the orange planting at Lo-kong-tung and the pummelo planting at Man Hang Village near TaiPo Market, New Territories, Hong Kong, both of which had been artificially inoculated with the red citrus ant. The scales parasitized by $C$. chinensis were most plentiful on branches having abandoned and disintegrating ant nests. 
Red scale containing the immature stages of Casca chinensis has been collected from under the finely woven "cloth" with which the leaf-nesting ant, Oecophylla, tightly encases the twigs of citrus. C. chinensis evidently oviposited through this cloth, indicating that it can find its host through chemotropic response only, the utilization of the senses of touch and sight not being necessary.

Unlike many parasitic Hymenoptera, the female Casca chinensis can find its host when the latter is located in an entirely artificial environmentfor example, an environment consisting of infested potato tubers enclosed in a wire basket. The female is apparently attracted directly to the scale itself, not only to the arboreal environment of such scale.

The "Casca Nursery." In 1947 the University of California arranged with Lingnan University of Canton, China, for the part-time service of Gressitt, a member of the Lingnan University staff. He was thereupon authorized to assemble and supervise a group of technicians to collect and propagate the natural enemies of California red scale and other pests of California agriculture native to China. The work accomplished by this group and the establishment in California of entomophagous species collected by the members has been reported by Smith and Flanders (1948, 1949, 1950), Gressitt and Flanders (1949), Flanders (1950, 1952, 1953a, 1953b), Flanders, Gressitt and DeBach (1950), and Gressitt and Djou (1950).

Although the red scale-feeding Casca was of particular interest, no live specimens were received in California until the spring of 1948. At this time shipments of citrus-infesting insects collected in the vicinity of Canton yielded 16 females of $C$. chinensis, which had emerged from five specimens of California red scale. None of these females, however, when placed with red scale, reproduced.

Additional Casca-parasitized red scales were not received until October, 1948, when shipments were made of material collected from citrus in Szechuan Province. The Casca from this material, however, consisted of males as well as of females and reproduced readily on red scale-infested potato tubers. Many thousands were released in California citrus orchards. After the first generation the laboratory stocks were found to consist of more males than females.

The Szechuan Casca was thought to be C. chinensis until 400 females of the Canton Casca were received during November. It was then noted definitely that the Casca females from Canton differed markedly in color from those originating in Szechuan. This difference was correlated with the capacity of the latter to reproduce generation after generation on red scale and the apparent inability of the former to reproduce for more than one generation. On the basis of this differentiation, Compere (1953) described the Szechaun Casca as C. wanhsiensis after the city Wan (fig. 3) and set up the Canton Casca as Howard's C. chinensis.

The 400 Casca chinensis females were largely derived from red scales collected from a single potted cycad (Cycas revoluta) on the campus of Lingnan University. This cycad originally had a very light natural infestation of red scale parasitized by $C$. chinensis. Early in the spring of 1948, 
however, it was artificially infested with red scale from twigs cut from infested orange trees in an orchard at Lo-kong-tung, 23 miles from the University campus. The red scale first used to infest the cycad was not known to be parasitized by $C$. chinensis. However, it was the red scale from these orange trees which yielded the 16 females of this parasite first received at Riverside.

The increase of the Casca-parasitized infestation on the cycad was apparently effected by repeatedly infesting it with red scale from Lo-kong-tung.

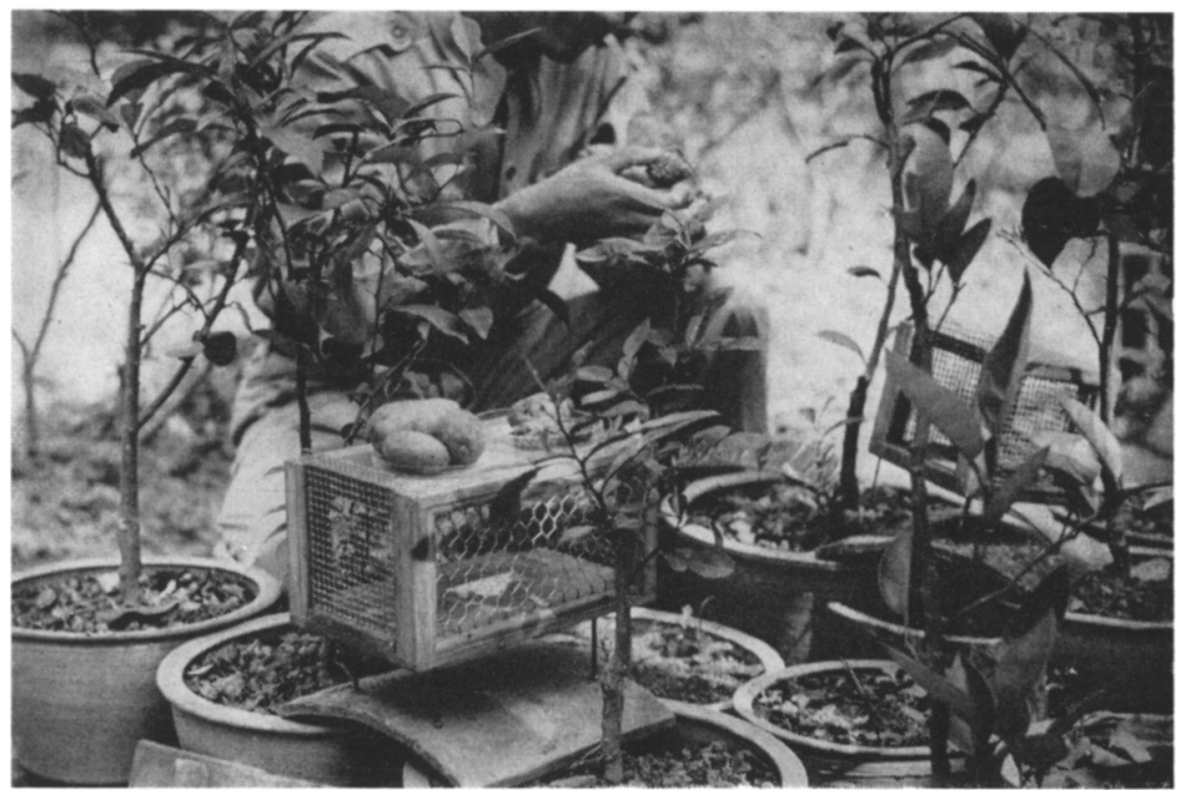

Fig. 6. Potted citrus trees in the garden of Lingnan University (August, 1949). These trees were naturally and artificially infested with red scale and used in the "Casca nursery." Red scale on laboratory-infested potato tubers placed within the wire boxes were found by the Casca females and parasitized.

In October, three potted cycads and three potted pummelos, already infested with a few Casca-parasitized red scale, were moved from Fati Island to the insectary garden.

By the middle of November, 1948, over 50 per cent of the scales on the original cycad were parasitized. Before the end of the month the collection of material from this plant for shipment to Riverside so reduced the scale population that reinfestation was necessary. This was accomplished by placing red scale-infested potato tubers on the fronds. Soon thereafter the red scale on these potatoes was observed to be parasitized by Casca chinensis. Before the end of the year several more cycads and potted pummelos from Fati Island had been introduced into the insectary garden.

These infested cycads and pummelos were expected to provide a convenient source of Casca chinensis for laboratory culture. This outdoor group of plants, however, through continuous reinfestation with the progeny of 
laboratory-grown red scale, became by force of circumstance the only culture of $C$. chinensis, the "Casca nursery."

The work in the Casca nursery was largely in abeyance during the spring and early summer of 1949 because Gressitt, assuming that the numbers of $C$. chinensis already sent to California were sufficient to start laboratory propagation, devoted practically all the efforts of his assistants to the collection of natural infestations of mealybugs and purple scale, as well as red scale. This work resulted in the establishment in California of Prospaltella

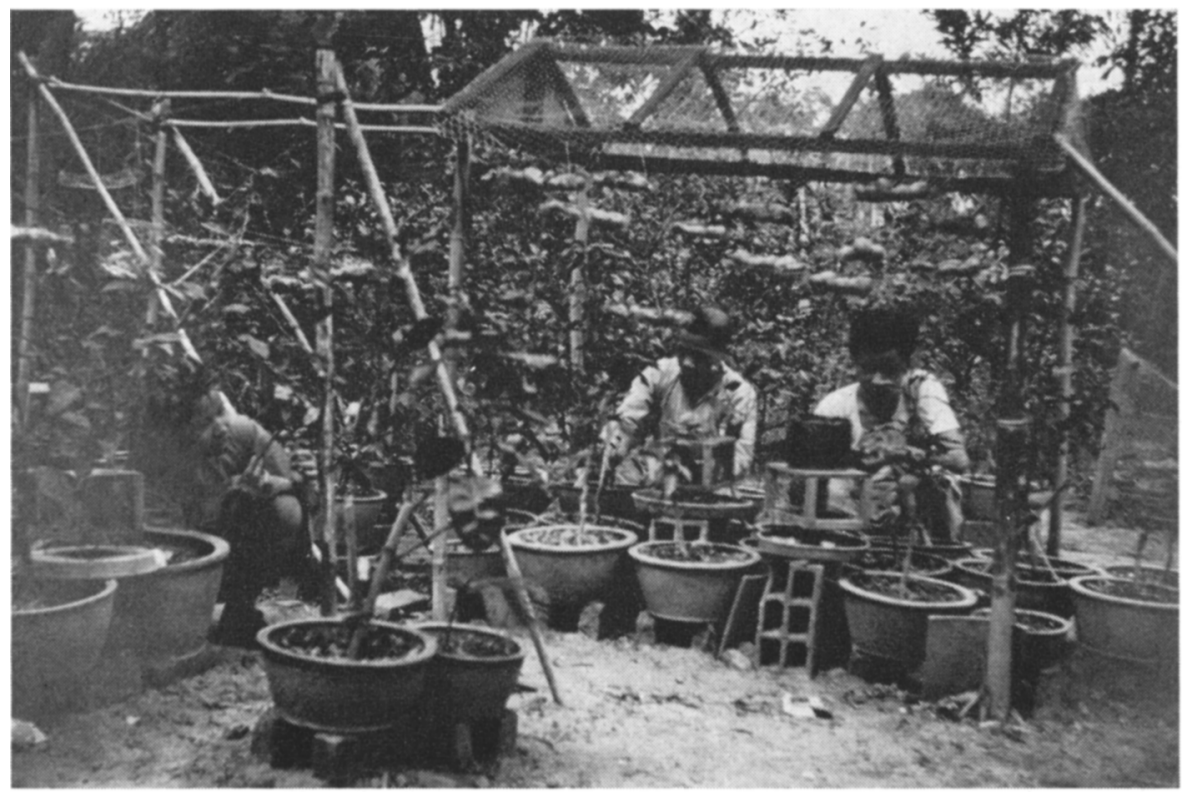

Fig. 7. The "Casca nursery" in the garden of Lingnan University, Canton, China. Note the wire baskets containing red scale-infested potato tubers suspended above potted pummelo plants. The red scale population on these plants was maintained by young scale dropping from the baskets. The $C$. chinensis populations developing on the red scale-infested potatoes were the progeny of females that emerged from the scale on the pummelos below. Casca-parasitized red scale on the potatoes was shipped to Riverside where the adult parasites emerged.

perniciosi on red scale, P.elongata Doz. on Glover's scale, and Aphytis lepidosaphes Comp. and Physcus sp. on purple scale.

At the same time, however, efforts were being made to start laboratory propagation of Casca chinensis, using red scale-infested tubers which had been exposed for a week or two on the fronds of the cycads or in hardwarecloth cages in contact with the potted pummelos (fig. 6). The suitability of the potato tuber as a host for red scale and its parasites has previously been described (Flanders, 1951). The use of the potato also permitted the sending of Casca-parasitized scale to California without danger of introducing citrus canker.

By August, 1949, it was evident that the problem of reproduction would 
not be easily solved. Casca chinensis females reared under laboratory conditions would not reproduce, and females collected under natural conditions would reproduce only females and these for only one generation. At this time it was suddenly discovered that $C$. chinensis in the insectary garden had nearly wiped itself out through its parasitization of the red scale on the cycads and potted pummelos.

Rejuvenation of the outdoor nursery began immediately. Reinfestation was then started on a continuous basis, laboratory-infested potatoes being placed in wire baskets so attached to bamboo poles that the potatoes hung 6 to 18 inches above the potted plants (fig. 7). The bamboo framework also supported a removable tin roof used to protect the plants against heavy rains.

Although the Communists took over the government of Canton and the surrounding area in October, 1949, the Casca nursery was maintained and enlarged. By the middle of 1950 it consisted of 8 cycads and 20 or more potted pummelos. These plants were constantly inspected so that they could be kept relatively free of insects other than red scale and its parasites.

The red scale-infested potatoes suspended above the potted pummelos served to continually reinfest the plants and to supply Casca-parasitized scale to send to California. The freshly exposed scale populations were found by the Casca females within a day or two. Since the complete development of their progeny in the potato-infesting red scale takes about one month, the parasitized infestations were removed and sent to California after an exposure period of one to two weeks. The scale-bearing surface of the potato was removed as a peel $1 \mathrm{~mm}$ thick and packed in absorbent tissue for shipment to California by air mail.

The first of such shipments, made on September 9, 1949, yielded only 15 Casca females. Subsequent shipments, however, produced a total estimated at nearly 10,000 , the scales on some potato peels being 100 per cent parasitized.

When it was definitely established that the Casca-parasitized red scale on the potato tubers yielded only female Casca which produced no progeny, the shipments to California of potato peels bearing parasitized red scale were stopped. Thereafter the Casca shipments consisted of adults collected from the potted pummelos and cycads. Some of these, as expected, produced a single generation of females on red scale-infested potatoes in the Riverside laboratory. The first of such females were observed on May 22, 1950, as two pupae in a scale attacked May 5 by a female which had been collected in the Casca nursery on April 28.

Early in 1950 it was clearly apparent that the culture of Casca chinensis in south China is relatively simple and efficient provided the parasite population has been well established on a dozen or so small pummelo plants which are kept out of doors and continually reinfested by means of laboratory-grown infestations on potatoes. This was in striking contrast to the complete failure to propagate $C$. chinensis indoors.

During January and February, 1950, however, the Casca parasitization on the pummelos and cycads was markedly reduced by competition from Aphytis lingnanensis and Aspidiotiphagus citrinus, species with shorter 
life cycles. (The latter species had not been a factor until a large pummelo bearing a relatively heavy infestation of red scale highly parasitized by Aspidiotiphagus was introduced into the garden.) To insure the continuous reproduction of Casca, the competing parasites had to be removed by hand. By the first of April, the Casca population had increased noticeably, and on June 20 Casca was by far the dominant parasite. Under these conditions, however, there was considerable hyperparasitism, the immature Casca females being parasitized by both sexes of the hyperparasite Marietta sp. and by the males of two undescribed species of Prospaltella. Eleven adults of Marietta and 12 males of Prospaltella were reared from 134 Casca-parasitized red scale.

By the middle of July Gressitt informed Flanders that the collection and shipment of 500 adults each week appeared feasible. In September, over 1,000 were collected per week, with almost all the red scale exposed in the garden being parasitized. The production situation in the Casca nursery as of October 1, 1950, was described to Flanders by Gressitt as follows: "Casca females were often found in numbers up to 30 on the underside of a single potato bearing fresh adult female scales. After it got to the point where 250 Casca could be collected in a short time, the exposed scale populations were kept more or less static because it was thought only a matter of a little time until the problem was solved."

The infestation on the exposed potatoes became so effectively parasitized during November, however, that crawler production and reinfestation of the pummelos were practically nil. It was then apparent that to maintain the outdoor culture of Casca, potatoes bearing parasitized scale would have to be removed periodically and replaced with those bearing reproducing scale.

The presence of Casca males first became known when unwanted parasites were removed by hand in the Casca nursery. At the time they were assumed to be $C$. chinensis males; no mating tests were made, and the few adults sent to California arrived dead. It was noted, however, that they were indistinguishable from the males of $C$. wanhsiensis.

When the Casca nursery was at maximum production there were more than 100 females to one supposed male of $C$. chinensis. This ratio raised the question, was the male essential for reproduction, or was reproduction completely parthenogenetic? Only one male was ever seen on the exposed infestation of red scale on potatoes, and that was on a long-exposed, very old infestation.

If the male Casca is that of $C$. chinensis, it is not attracted to red scale as such, but searches for the female on citrus and cycad. If the host of this male is not the red scale, it is a species closely associated ecologically with red scale, since the latter is of necessity the host of its parent; furthermore, on citrus the adult male is always found in the vicinity of red scale, presumably at hand to mate with the females emerging therefrom. A careful examination of the various plants in and near the Casca nursery, however, failed to reveal parasitized insects that might have yielded the Casca male.

The Casca nursery was abandoned in January, 1951, because of the pressure of political events in Communist China. Small wire cages containing 
Casca-parasitized red scale on potatoes were then taken to British-controlled New Territories and suspended from pummelo trees at Hong Lok Yuen near TaiPo Market. An attempt to establish a new Casca nursery on the property of S. K. Cheng at Shatin failed because of the lack of adequate help and facilities.

Field-collected, presumably mated females of Casca chinensis were released in California in red scale-infested citrus orchards, including the Biological Control grove on the Riverside campus. One Casca-parasitized red scale was found on a lemon tree. This constituted the only recovery in California of this parasite.

The failure to establish Casca chinensis and C. wanhsiensis in California may have been due to faulty timing of the releases, the colonization of $C$. wanhsiensis being attempted on the assumption that the male develops only as a primary parasite, that of $C$. chinensis on the assumption that males were unnecessary for reproduction.

Biparental Reproduction Established. The sixth and most recent attempt to introduce Casca chinensis from south China into California began in the fall of 1953. This was possible because about 300 square miles of south China remained under the control of Great Britain, an area designated New Territories, adjacent to Hong Kong.

The demonstrated effectiveness of Casca chinensis in controlling red scale in the insectary garden of Lingnan University had emphasized the desirability of introducing the parasite into California. In this attempt Flanders undertook the exploratory and experimental work in south China, ${ }^{s}$ and Fisher handled the imported material received at Riverside.

Through the coöperation of the Lutheran Mission of Hong Kong and its pastor, Brede Mella, living and laboratory facilities, as well as plantings of 12 species of host plants of red scale, were provided at the compound of the Bible Institute near TaiPo Market (fig. 8), a town in the center of New Territories and about 80 miles south of Canton.

All species of citrus occur in this area, the most widely distributed being the pummelo, which is largely limited to the Chinese villages. At least 400 of the 3,000 mature pummelo trees estimated to occur throughout the area were carefully examined for red scale. About one in twenty was found to be infested with one or more red scales. All the infested leaves and twigs (1/2 inch or less in diameter) were brought into the laboratory for microscopic examination. During a 13-week collecting period, 1,927 leaves and twigs ( 6 inches or less in length), each infested with one or more healthy mature red or yellow scales, were collected.

The first collection of red scale parasitized by Casca chinensis was made on December 1, 1953. It consisted of a single red scale from which two females of $C$. chinensis were reared. This red scale was the only one found during an hour of searching a very clean and vigorous pummelo tree in a Chinese village about one mile southeast of TaiPo Market.

\footnotetext{
* This work was undertaken with the permission and coöperation of the Hong Kong Department of Agriculture, Fisheries, and Forestry. The assistance of Director W. J. Blackie and the citrus entomologist, P. Y. So, is gratefully acknowledged.
} 
The general scarcity of Casca-parasitized red scale is indicated by the fact that the next specimen was not found until December 20. This scale was placed in a glass vial so that the developing parasites within the scale could be viewed by transmitted light. Three nearly full-fed larvae of $C$. chinensis, which soon became prepupae, were revealed. Four days later, however, two of these prepupae were mummified by the larvae of an endoparasitic hyperparasite. Since it was Flanders' thought that such a habit characterized the

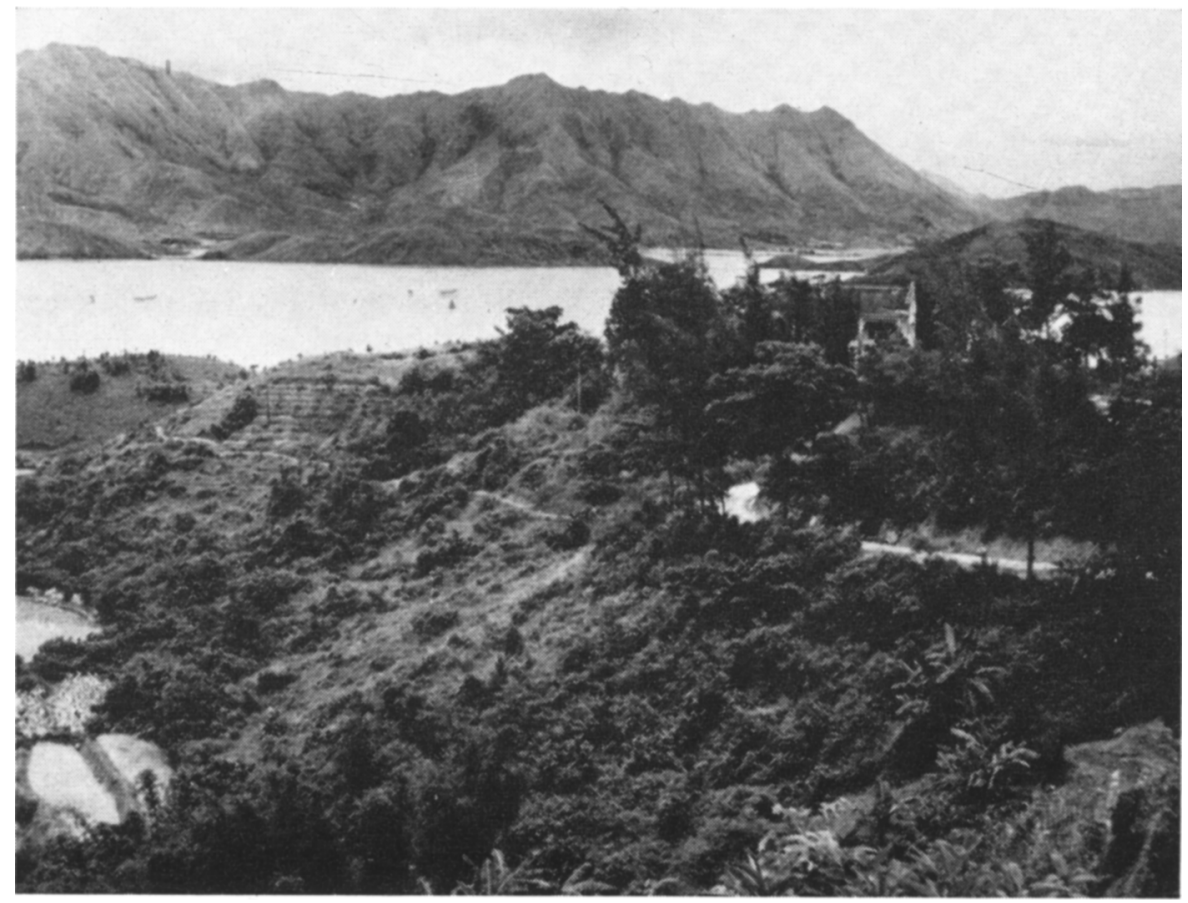

Fig. 8. Topography of the region near TaiPo, Kwangtung Province, inhabited by Casca chinensis. The buildings are those of the Lutheran Bible Institute in which the University of California Biological Control Laboratory was located during the nine-month period ending July, 1954.

development of the Casca male, the emergence of two Casca males was expected. Instead, however, 14 days later two females of the hyperparasite Marietta sp. emerged from the two mummified prepupal Casca. This endoparasitic behavior of Marietta was extraordinary, since species of the same genus were reared as ectoparasites of Aphytis.

Casca chinensis was found in abundance only in a small pummelo orchard about one mile north of TaiPo Market. Here the red scale ${ }^{9}$ was quite plentiful on several branches of three trees. Two nests of the ant Oecophylla smaragdina were found on the largest of these trees. When this Casca-parasitized infestation was found, most of the scales had been destroyed by $C$. chinensis. Nevertheless, approximately 50 were collected, and these yielded $120 \mathrm{C}$.

${ }^{9}$ Identified by Howard L. McKenzie, April 8, 1954. 
chinensis females. This was 70 more than the total number of $C$. chinensis previously collected from all other localities.

Since the red scale in this orchard largely disappeared through the action of parasites and the collection of scale for parasite rearing, about five of the trees were reinfested by placing red scale-infested potato tubers on the branches. The young scale that migrated to the tree surfaces were destroyed, apparently by predatory coccinellids, thrips, and dusty wings.

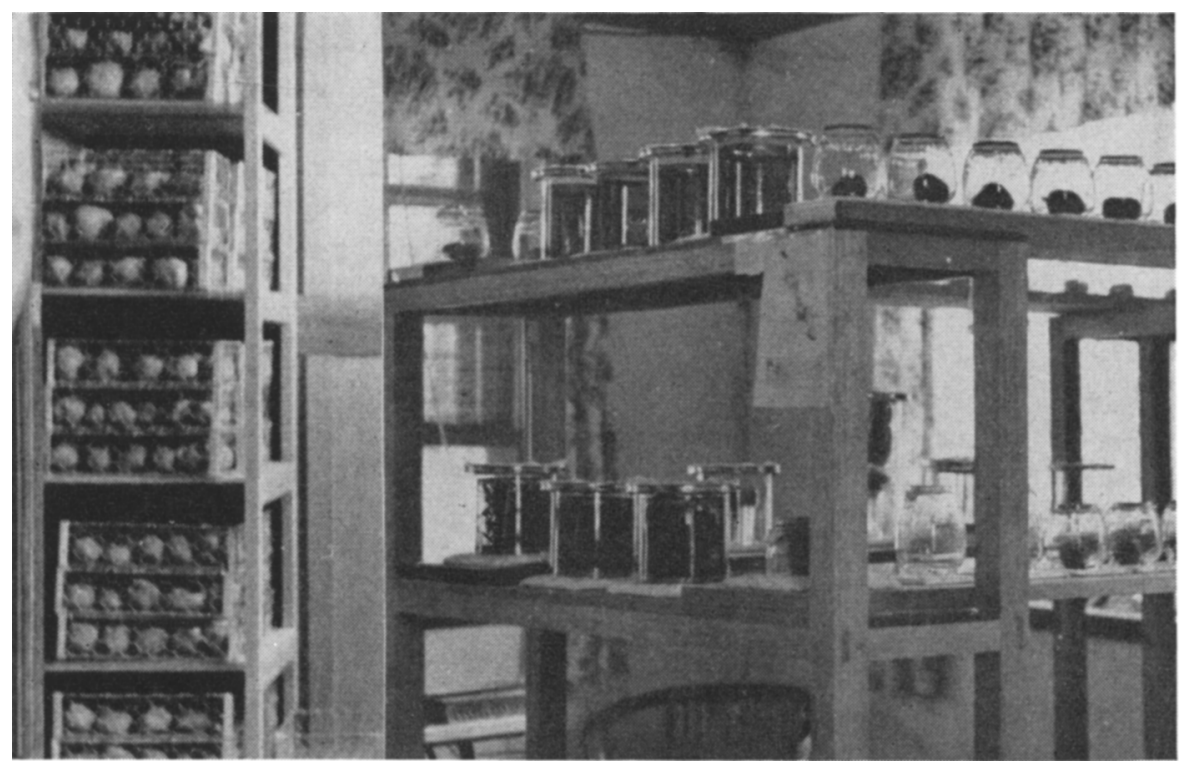

Fig. 9. Parasite-rearing room of the University of California Biological Control Laboratory at the Lutheran Bible Institute in New Territories, south China. The cabinet contains baskets in which potato tubers were infested with red scale. The glass parasitization cages used in testing the reproduction of Casca consisted of lantern globes on cloth pads.

The laboratory-reared red scale, after being exposed for one to five weeks and then returned to the laboratory, yielded 370 female Casca (fig. 9) . Fifty red scale-infested potatoes, exposed for the week ending June 14, yielded Casca females as follows:

June $27 \ldots \ldots \ldots .3$ females

June $28 \ldots \ldots \ldots .5$ females

June 29 ........29 females

June $30 \ldots \ldots \ldots 22$ females

July $1 \ldots \ldots \ldots 24$ females

July $2 \ldots \ldots \ldots 27$ females

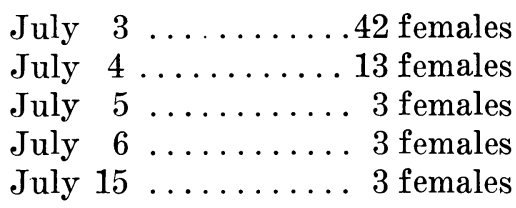

July $3 \ldots \ldots \ldots .42$ females

July $4 \ldots \ldots \ldots 13$ females

July $5 \ldots \ldots \ldots .3$ females

July $15 \ldots \ldots \ldots .3$ females

After April, parasitization of the exposed scale markedly decreased, perhaps because the foliage was beaten almost daily during May and June in order to collect adults of Casca chinensis. This beating program yielded 150 females and 10 males, the maximum numbers collected in a single day being 10 females and 1 male collected on June 25 and 10 females on June 26. 
The first adult males to be collected under natural conditions were obtained by beating the leaves of pummelo trees on May 30, 1954. Presumably mated females had first been collected by this method on January 28, 1954. The field collection of the Casca male is more difficult than that of the female, since it is half the size and lacks the very noticeable white band around the middle third of the female's body. It was by mating laboratory-produced females with field-collected males that the reproduction of $C$. chinensis was definitely established as biparental.

From April 22, 1954, to March 10, 1955, 657 field-collected adult females of Casca chinensis were received alive at Riverside. These were from collections made at 14 different localities within 10 miles of TaiPo Market. During a four-month period in 1954, 229 of these were released on a pummelo tree in the Biological Control grove on the Riverside campus. No recoveries were made from these releases, possibly because strong winds stripped the leaves and fruits from these trees late in December. The field-collected Casca females retained in the laboratory for experimental reproduction yielded one generation consisting of 175 females. Apparently not all of the field-collected females were mated, as progeny was obtained from only one third of the females in 72 shipments.

Of 54 females under close observation, 11 were observed feeding on host fluids through ovipositor punctures. This feeding, which is not common, apparently occurred only on immature stages of the scale, particularly the prepupa of the male scale.

\section{THE QUEST FOR THE AGENCY OF MALE DEVELOPMENT}

The adult progeny of the mated Casca chinensis female invariably consists of females, the red scale being the only host known to be suitable for the development of the female. The production of males must therefore be limited to the unmated females, as is known to be the case with other aphelinids, such as Coccophagus scutellaris (Dal.), C. rusti, and C.lycimnia (Walk.). Mated females of such species may deposit unfertilized eggs, but such eggs cannot develop because their environment is unsuitable (Flanders, 1937). When the mated Casca female deposits unfertilized eggs in the body fluids of the red scale, such eggs suffer the same fate as those likewise deposited by unmated females. Some of the eggs from unmated females, however, must be deposited under highly specialized conditions, conditions which do not stimulate oviposition by mated females but which are essential for the development and hatching of unfertilized eggs. As in other species of aphelinids, mating may effect changes in the oviposition response.

With the very closely related species of Casca parasitic in yellow scale, it is highly significant that under field conditions males and females develop synchronously in the same individual scale. Under laboratory conditions, however, the unmated female oviposits in yellow scale but, like the red scalefeeding $C$. chinensis, produces no progeny until after mating. In both cases the missing factor is the condition under which the embryonic male will develop, a condition apparently correlated with the presence of mated females. 
However, because of the possibility that the male of Casca chinensis completes its development only as a secondary parasite of the coccid host, as reported by Taylor (1935) for C. parvipennis, many tests were made in south China and in California in an attempt to determine whether or not the male followed the pattern of hyperparasitic development known to occur in certain nongregarious species of aphelinids.

Unmated females varying in age from 24 hours to 53 days were tested for hyperparasitic oviposition (male production). Newly emerged, unmated females oviposit in red scale almost as readily as mated females, as readily if inactivated for 30 to 50 minutes by exposure to $\mathrm{CO}_{2}$ gas.

In an attempt to obtain males, various combinations of secondary and primary hosts were tested, using unmated females of Casca chinensis. In a long series of tests made by Flanders in China and Fisher in California, the several instars of Prospaltella perniciosi, Comperiella bifasciata, Aspidiotiphagus citrinus, Aphytis lingnanensis, and female Casca chinensis were used in all instars of Aonidiella aurantii en masse on white rose potato tubers and mature green lemons. Additional hosts tested were Aonidiella citrina containing immature Comperiella bifasciata, nonparasitized eggs of the moths Platynota and Sitotroga, the eggs of these species parasitized by Trichogramma minutum, and citrus mealybugs containing immature stages of Allotropa and Pauridea. (The possibility that the Casca male is a tertiary parasite-that is, a parasite of Marietta, which is parasitic on the prepupa of $C$. chinensis - was considered early in April, 1954, but remains to be tested.)

It was arranged for unfertilized eggs of Casca chinensis to be deposited in red scale both before and after deposition of fertilized eggs by the several primary parasites, including Casca; the unmated Casca oviposited first, then the same hosts were oviposited in by Casca, Prospaltella, and Comperiella, and vice versa. In the majority of tests, however, the procedure was to offer parasitized red scale to the unmated Casca. In several instances Casca, Comperiella, and Prospaltella oviposited in the same individual seales, so these particular hosts were multiple-parasitized. Some of these hosts died; some produced Prospaltella or Comperiella; none yielded Casca, even when the Casca oviposited first.

In one experiment in which 20 mature red scales were attacked by unmated Casca and then 12 to 72 hours later by mated females, 11 of the scales yielded only female Casca. The remaining scales died from the effects of the attack but yielded nothing, although some undoubtedly contained unfertilized eggs of Casca.

Under laboratory conditions the unmated female occasionally oviposited in the eggs of the dusty wing, Spiloconis picticornis Banks (Coniopterigidae), a common predator on red scale in China, the egg of this host being either newly deposited or having a developing embryo. The Casca eggs were clearly visible through the eggshell of the host. Had they hatched, development could have been easily observed. The possibility exists, however, that the hatching of the unfertilized Casca egg in the dusty wing egg depends on the presence of its primary parasite, Oligosita sp. 
The possibility that the Casca male develops hyperparasitically in prepupa and pupa of Aphytis lingnanensis was tested, as was the possibility that it develops as an ectoparasite of the red scale paralyzed by $A$. lingnanensis.

Early third-instar female red scales were exposed to female Aphytis lingnanensis. When oviposition was completed, the waxy cover of the scale was removed and the newly laid Aphytis egg removed and discarded before its mucilaginous coating hardened. Twelve- to 24-hour-old unfertilized Casca eggs $(0.08 \times 0.16 \mathrm{~mm})$ freshly extracted from parasitized red scale were placed in the exact spot that had been occupied by the Aphytis egg. This transfer took place 12 hours after deposition, since any earlier than this the Casca eggshell is not firm enough to be handled. The transplanted Casca eggs dried out within three days, although the waxy scale coverings had been replaced.

The Casca chinensis females received in Riverside in January readily oviposited in red scale on potatoes and grapefruit, and produced about 100 female progeny. It was then demonstrated that a gravid red scale contains enough food for the complete development of 10 Casca females.

During January and February the following tests were conducted at laboratory temperatures ranging from $76^{\circ}$ to $78^{\circ} \mathrm{F}$ and a relative humidity ranging from 50 to 60 per cent. Under such conditions the minimum life cycle of the Casca female ranges from 25 to 27 days, depending on the number of individuals developing in the individual host. The 25-day cycle occurs when 6 to 10 individuals are in a single third-instar host; the 27-day cycle occurs when there are 1 to 5 individuals in a third-instar host.

Nine presumably mated females six-plus days of age (collected by beating pummelo trees near TaiPo Market) were placed for a 4-day period on a grapefruit bearing only 17 third-instar red scales. Fertilized eggs, as demonstrated by the adults produced, were deposited in nine of the scales as follows: 5 eggs in 4 scales, 4 eggs in 4 scales, 6 eggs in one scale.

In a final attempt to induce the development of the male egg by the presence of newly hatched female larvae, a number of ovipositions were made in an infestation of red scale on grapefruit consisting of 35 third-instar red scales. The scales on the fruit were numbered consecutively with India ink.

During a 24-hour period 14 of the scales received ovipositions by presumably mated females; two were observed ovipositing together in a single scale. Five days later unmated females oviposited in 10 of these 14 scales, one scale receiving two ovipositions that lasted 15 and 20 minutes. For one week all of the 35 scales were exposed to attack by more than 10 unmated females.

On February 15, the presence of developing Casca larvae was detected in some of the scales parasitized by mated females on February 1 . This is possible because the content of the red scale on grapefruit, including the immature instars of Casca, is visible if, while the scale is shaded from direct light, it is viewed in light transmitted through the flesh of the grapefruit. Six scales thus determined as parasitized were transferred to glass vials on February 16. One scale dried up because of injury in handling, but the others all yielded adult female progeny - as many as seven in one case. The 
10 adult females that developed from one scale were the progeny of two parents.

One scale is of particular interest. After parasitization by a mated female, three unmated females oviposited in it, each on a separate date (Feb. 5, 9, and 13). This scale yielded three adult females and three female larvae which spun cocoons but died before voiding all their meconia. Peristalsis of the midgut of one larva was observed as late as February 24.

Unmated females oviposited in six other scales, three of which had previously been attacked by mated females. No progeny resulted from any oviposition by unmated females. Pupae in two scales were exposed for 24 hours to attack by unmated females; however, although oviposition was attempted, no progeny developed.

An attempt was also made to determine the effect of repeated ovipositions by unmated females on the suitability of the scale host for the development of the Casca male. Unmated females oviposited on a grapefruit bearing 55 numbered third-instar red scales. Five scales each received an oviposition lasting more than 20 minutes. Each of four other scales received two or three ovipositions by unmated females on two successive days, some of the ovipositions lasting as long as 45 and 50 minutes. For two weeks all scales were continuously exposed to unmated females. All scales remained healthy.

On February 20, 10 females of Habrolepis rouxi were added to the cage containing the grapefruit used in the preceding test. These were removed February 26. No Casca males were obtained.

First-and second-instar red scales exposed to Prospaltella for four days ending February 25 were exposed to 11 unmated Casca. Oviposition in firstinstar red scale and prepupal male scale was observed, but no progeny resulted.

\section{DISCUSSION}

When it was discovered that the unmated Casca chinensis female, several days after emergence, oviposited in California red scale almost as readily as did the mated female, and that the eggs deposited underwent little if any development, the possibility that the male was hyperparasitic greatly diminished. In all the known instances in which hyperparasitic male-producing eggs are deposited in the body fluids of either coccids or the parasites of coccids, embryonic development is completed. The male-producing eggs of Coccophagus rusti Comp., for example, when deposited in the body fluids of Saissetia oleae Bern., complete their embryonic development, but the larvae therefrom are unable to utilize this host for food (Flanders, 1952).

Fisher found that in newly gravid red scale on potato the male-producing egg deposited by the unmated female of Casca chinensis may remain for as long as 34 days at $80^{\circ} \mathrm{F}$, apparently viable and without being phagocytized. It is evident that the development of the male embryo in $C$. chinensis eggs deposited in red scale is inhibited either by the presence or absence of some substance.

It was found that the age of the red scale does not bring about the formation of any substance conducive to the development of the Casca male. Un- 
mated Casca females were induced to oviposit in red scales that had produced most of their complement of progeny, but no males of Casca were thus produced.

When a parasitized red scale yields only one Casca female, one or two unfertilized (male) eggs have probably been deposited with the fertilized egg, since as a rule the Casca female deposits three or four eggs with one insertion of the ovipositor. In other aphelinid species of this type mated females deposit unfertilized as well as fertilized eggs in hosts unsuitable for male development; with Casca it was thought that the mated female might induce a change in the nature of the primary host which would permit the development of the male. The tests noted above, however, eliminated this possibility.

Repeated insertions of the ovipositor are not necessarily injurious to the third-instar scale, nor do they render it suitable for the development of the Casca male. Over 20 such scales have been observed to develop and reproduce after being subjected to such insertions of the ovipositor of Casca from 1 to 36 minutes.

It appears that in any species of the genus Casca in which both sexes develop within the same individual host, as in the species attacking Florida red scale and yellow scale, either the adult males and females emerge at the same time or the males emerge one or two days after the females. Since in most parasitic Hymenoptera the developmental period of the male is a day or two less than that of the female, the male-producing egg of Casca spp. is probably deposited after the female egg has started its development.

The fact that no male of Casca chinensis has been reared in the laboratory at Riverside from the hundreds of red scale collected from pummelo trees in south China is inconclusive evidence that the red scale is not its host. The possibility that the $C$. chinensis male does develop in red scale is indicated by the fact that the total number of red and yellow scales parasitized by Casca spp., collected from pummelo during eight months of intensive searching, yielded from red scale 197 adults of $C$. chinensis and from yellow scale 178 adults of a Casca very closely related to $C$. chinensis. The Casca adults from yellow scale, unlike those from red scale, included males: one scale yielded four males, each of three scales yielded two males and one female.

The distribution in south China of yellow scale parasitized by Casca sp. is such that the probability of collecting scales yielding 197 females without males is about as high as with the red scale and $C$. chinensis. In 1951-52, 34 shipments of yellow scale collected by T. C. Maa from Agalma sp. in Formosa yielded over 600 females of this Casca sp. and no males.

In the laboratory at Riverside, 28 mated females of the Casca parasitic in yellow scale produced 134 female offspring and no males. Repeated attempts to obtain males from unmated females failed, yet under field conditions the male develops in yellow scale.

Three circumstances involving the production of males in certain closely related species of Casca suggest that the continued development of the unfertilized egg is contingent on the deposition of that egg in a particular 
stage of an early larval Casca female, the larval male then being briefly hyperparasitic but completing its development as a primary parasite of the scale host.

These circumstances are (1) the impossibility of obtaining males from unmated females in the absence of mated females, as with the yellow scale Casca and C. wanhsiensis; (2) the fact that a host scale may yield only males (as many as four), as is known to be the case with the yellow scale Casca and C. wanhsiensis; and (3) the emergence of both sexes from the same individual host, with the male emerging either at the same time as, or a day or two later than, the female, as with the yellow scale Casca and C. smithi.

In one of the tests described above, in which a red scale containing six larvae of Casca chinensis was subjected to three ovipositions at 4-day intervals by unmated Casca females, only three of the larvae completed development. The other three, which died as full-fed larvae, may have been males.

The successful culture of Casca chinensis may not be contingent on the discovery of the method of male development. Perhaps, as was apparently the ease with $C$. wanhsiensis, male production will oceur when cultures are initiated with populations of host and parasite in ratios and in densities which will ensure the deposition of unfertilized eggs in hosts that will stimulate embryonic development.

The final method of ascertaining the host of the male, if it proves not to be associated with the red scale, may be the isolation in small glass vials of all plant material bearing infestations of various insects (scales, mealybugs, moth eggs, white fly pupae) collected within areas adjacent to and including those in which there is an abundance of red scale parasitized by female Casca chinensis. The daily examination of such material would be necessary. A detailed analysis of all material in vials containing male Casca should indicate the host on which it developed. To accomplish this it may be necessary to promote Casca-parasitized red scale populations by placing nests of Oecophylla smaragdina on citrus trees artificially infested with red scale.

If Casca chinensis is a host-specific parasite, it must be able to survive at very low red scale densities, since the other natural enemies of red scale, all of which appear to have several species of hosts, generally keep the scale on susceptible citrus trees at low densities. Under natural conditions in south China, where the red scale population is not being artificially maintained and where ants do not interfere with the competitive action of other natural enemies, Casca is not found as often as are the nonspecific parasites, Aphytis spp., Aspidiotiphagus, Comperiella, and Prospaltella. Under such conditions Aspidiotiphagus citrinus is usually the most abundant species.

A specific parasite, such as Casca chinensis appears to be, would be expected to possess a highly developed sensitivity to the presence of a host. It is considered significant that $C$. chinensis and Prospaltella perniciosi were the principal parasites of red scale attracted to red scale on potato tubers in south China during the spring of 1954, when hundreds of such infested potato tubers were placed on eitrus or eycad for a month or more. During 
the latter part of 1949 and throughout 1950, when red scale-infested potatoes were placed continuously in wire baskets above but not touching potted pummelo trees, the only primary parasite reared from the red scale was the female of $C$. chinensis, although the adults of Aphytis and Aspidiotiphagus had been observed on such red scale-infested potato tubers.

\section{CONCLUSION}

In south China Casca chinensis is apparently able to maintain itself on extremely low populations of red scale; it has even been collected from citrus trees which are apparently free from such scale. It may become abundant, however, on dense populations of red scale on orange and pummelo, provided that its reproduction suffers no interference from dirt and grime or from competition with the general parasites, Aphytis and Aspidiotiphagus, and the general predators, including species of coccinellids, nitidulids, coniopterygids, and spiders. Ant-induced populations apparently provide conditions favorable for $C$. chinensis reproduction, since the ant maintains the immediate environment of the scale in a highly sanitary condition and keeps it relatively free of other natural enemies. The female of $C$. chinensis when ovipositing is not readily disturbed.

It has been determined that Casca chinensis is relatively scarce in the coastal areas of southeast China; that in these areas it becomes abundant and is the dominant natural enemy in red scale populations that are ecologically correlated with populations of the ant Oecophylla smaragdina; that it can effectively control the red scale under certain conditions out-of-doors; that no other hosts are known, although extensive collections of various diaspine scale insects have been made in many parts of the world; that it is biparental in reproduction; that mated and unmated females are attracted to red scale and oviposit in it; that when the mated female is not part of the environment, embryonic development in the unfertilized egg is inhibited at the moment of oviposition in red scale; that mated females produce only female offspring; that the temperature requirements for Casca reproduction largely coincide with those of red scale.

If the development of the male of Casca chinensis is markedly different from that of the structurally indistinguishable species that is parasitic in the yellow scale and from the red scale-feeding form of $C$. wanhsiensis, it may be necessary, in order to solve the problem, to make a systematic collection of all possible hosts.

The successful control of red scale in California citrus orchards by Casca chinensis remains a possibility until it is demonstrated that $C$. chinensis is not adaptable to California conditions. Such a demonstration, however, cannot be made until the techniques of production and colonization employed are adequate.

\section{LITERATURE CITED}

COMPERE, HAROLD

1953. An appraisal of Silvestri's work in the Orient for the University of California, some misidentifications corrected, and two forms of Casca described as new species. Portici Lab. Zool. Gen. e Agr. Bol. 33:36-46. 
Craw, Alexander

1907. Report of the Division of Entomology for the year ending December 31, 1906. Board of Agriculture and Forestry, Territory of Hawaii. Hawaiian Gazette Co. pp. 139-63.

Flanders, Stanley

1937. Ovipositional instincts and developmental sex differences in the genus Coccophagus. California Univ. Pubs. Ent. 6:401-22.

1944. Observations on Comperiella bifasciata, an endoparasite of diaspine coccids. Ent. Soc. Amer. Ann. $37: 365-71$.

1948. Biological control of yellow seale. California Citrog. 34:56, 76-77.

1949. George Compere, pioneer in the biological control of red scale. California Citrog. $34: 160-62$.

1950. An enemy of purple seale recently established in California. California Citrog. $36: 64-65$.

1951. Mass culture of California red scale and its golden chalcid parasites. Hilgardia $21: 1-42$.

1952. Another parasite of purple seale established in California. California Citrog. $37: 234,256-57$.

1953a. Hymenopterous parasites of three species of oriental scale insects. Portici Lab. Zool. Gen. e Agr. Bol. 33:10-28.

$1953 b$. Variations in susceptibility of citrus-infesting coceids to parasitization. Jour. Econ. Ent. $46: 266-69$.

1954. Casca's elusive husband. California Citrog. 39:343, 352.

1957. Fig scale parasites introduced into California. Jour. Econ. Ent. 50:171-72.

Flanders, Stanley E., J. L. Gressitw, and Paul DeBach

1950. Parasite of Glover's scale established in California. California Citrog. $35: 254-$ 55.

GressitT, J. L. and Y. W. DJoU

1950. Introduction to the study of citrus seale insects and their biological control in China. Lingnan Nat. Hist. Survey and Mus., Spec. Pub. 13:1-19. [In Chinese with English summary.]

Gressitr, J. L., and S. E. Flanders

1949. New developments in the transport of beneficial insects. Jour. Econ. Ent. $42: 150$.

HowARD, L. O.

1907. New genera and species of Aphelininae with a revised table of genera. U. S. Dept. Agr., Ent. Tech. Ser. 12:83-84.

Nicholson, A. J.

1933. The balance of animal populations. Jour. Anim. Ecol. 2(suppl. 1) :132-78.

QuaYle, H. J.

1911. The red or orange scale. California Agr. Exp. Sta. Bul. 222:99-150.

Silvestri, F.

1928. Preliminary report on the citrus scale insects of China. 4th Internatl. Cong. Ent. (Ithaca) Trans. 2:897-904.

Smith, HaRry S., and Stanlet Flanders

1948. Search for parasites of red scale re-oriented. California Citrog. $34: 4,17$.

1949. Recent introductions of entomophagous insects into California. Jour. Econ. Ent. 42:995-96.

1950. The search for natural enemies of citrus pests. California Citrog. 35:362, 376.

TanaKa, TYozaburo

1954. Species problems in Citrus. Jap. Soc. Prom. Sci. Tokyo. 152 pp.

TAYLOR, T. H. C.

1935. The campaign against Aspidiotus destructor Sign. in Fiji. Bul. Ent. Res. 26: $1-102$. 

The journal Hilgardia is published at irregular intervals in volumes of about 600 pages. The number of issues per volume varies.

Subscriptions are not sold. The periodical is sent as published only to libraries, or to institutions in foreign countries having publications to offer in exchange.

You may obtain a single copy of any issue free, as long as the supply lasts; please request by volume and issue number from:

Agricultural Publications

Room 22, Giannini Hall

University of California

Berkeley 4, California

The limit to nonresidents of California is 10 separate issues on a single order. A list of the issues still available will be sent on request. 